\title{
MULTI-RESOLUTION MODELING FOR ADAPTIVE UAV SERVICE SYSTEMS
}

\author{
Bernard P. Zeigler \\ University of Arizona \\ and RTSync Corp. \\ zeigler@rtsync.com
}

\author{
Doohwan Kim \\ RTSync Corp. \\ Chandler AZ, USA \\ dhkim@rtsync.com
}

\begin{abstract}
With the advent of Unmanned Autonomous Vehicles (UAV), new kinds of systems of systems (SoS) that provide specific services may be on the horizon. We recognize that beyond basic technology requirements, such UAV-based service systems may be subject to a multiplicity of system engineering objectives. An allinclusive model would be able to provide the basis for decision making in each of such categories as payload requirements, on-board-energy constraints, locations of depots/launch sites, and so on. Multiresolution modeling helps us to construct a collection of partial models, each oriented to one or more objectives. In this paper, we discuss a Modeling and Simulation methodology that is based on Discrete Event System Specification (DEVS) and System Entity Structure (SES). As implemented in the MS4 Me integrated development environment, it provides a practical approach to multiresolution model-based system design of UAV-based service systems.
\end{abstract}

Keywords: Systems of systems, multiresolution modeling, unmanned autonomous vehicles, adaptive sustainment systems, DEVS Markov models.

\section{MULTI-RESOLUTION FAMILIES OF MODELS}

Multi-resolution modeling (MRM) is essential for exploratory analysis of complex adaptive Systems of Systems (SoS) design spaces because it is neither cognitively nor computationally possible to keep track of all relevant variables and causal relationships (Davis. and Bigelow 1998). A typical multiresolution scenario applicable to defense investigates the operational differences between low-level military entities such as individual tanks and the aggregated high-level units, e.g., battalions or platoons when moving in a battlefield. Attributes of an aggregated entity like a tank battalion are often determined by applying an aggregation mapping to the attributes of its individual entities. The mapping can group a set of tanks to a single tank battalion together with a function to derive holistic attribute values, e.g., an average speed of a tank battalion, from the constituent individual tank speeds (disaggregation is the inverse mapping). Here, the base model is typically "more capable" and requires more resources for interpretation and simulation than the lumped model. By the term "more capable", we mean that the base model is valid within a larger set of experimental frames (with respect to a real system) than the lumped model. Here, we note that the terms "base" and "lumped" are terms employed with the framework to denote the full range of possible pairs of models in which the first is more capable (e.g., more detailed, disaggregated, high resolution, fine 
grained) than the second (less detailed, aggregated, low resolution, coarse grained). Some typical distinctions often drawn between base and lumped models with respect to agent modeling, discussed in (NPS Faculty 2017; Zeigler et al. 2018a) are objectives, representation entity attributes and variables, interaction processes, timing mechanisms, computational complexity (scope/ resolution/ interaction product). However, the important point is that within a particular experimental frame of interest the lumped model might be just as valid as the base model. Furthermore, the trade-off between performance and accuracy is a fundamental consideration where performance refers to the computational resources used in a simulation run and accuracy refers to the validity of a model with respect to a referent system within an experimental frame. Use of computational resources tied to a simulator's time and space demands in generating the model's behavior are correlated with its scope/resolution product where scope refers to how much of the real world is represented, resolution refers to the number of variables in the model and their precision/granularity.

Models should be built in an incremental manner with continuous engagement and validation from the subject matter experts (SMEs) and their mapping to the experimental frames. This pairing allows the selection of the correct resolution of the model. This allows the development of early insight into the objective of the modeling, provides a holistic view of the system under study, provides a testing framework for the target, explains the target's behavior early in the M\&S development cycle and serves as the foundation to add more complexity to the subsequent models. Parallel development of the experimental frames provides the experimentation and data collection requirements for the model and the computational requirements of the underlying simulation platform.

The incremental manner from lower complexity to higher complexity works when one tries to build models from top-down. However, there may be situations that in high fidelity models are already present and one needs to bring them together to develop a larger SoS model. This includes the incorporation of legacy models and simulators. In that situation, lumping needs to be carefully managed as information is lost in aggregation if not justified by valid abstractions such as from the underlying fundamental science (e.g., physics, chemistry, etc).. This is then further supported by systems morphisms and homomorphisms to ensure that there is continued correspondence between the model family (containing base, lumped and higher fidelity) and the model hierarchy.

\subsection{MRM construction methodology}

Zeigler et al. (2018b) provides a MRM construction methodology that applies resolution and composition operations to create a multi-resolution family of simulation models. Roughly, given requirements and constraints of the problem, consider a model that satisfies all such requirements and constraints as the target base model. Create lumped models by making assumptions about the base model, including relaxing of constraints and dropping of requirements. Create higher resolution models by removing assumptions that were previously added while including more refined representations to address the affected constraints and requirements, meanwhile checking for consistency of predictions between related base and lumped models. The targeted base model is the one achieved when all assumptions that have been made are removed in this iterative process.

\section{AUTONOMOUS UNMANNED VEHICLE FLEET}

We now apply this methodology in an example of a system engineering application, an autonomous unmanned vehicle fleet providing emergency ambulance service. Following Dahmann (2018), consider the problem of first responders to catastrophic events providing emergency rescue and relief. Such a service requires coordination of multiple systems (so is a SoS) with complex interconnected networking and requires adaptation to the different challenges posed by different calls to service. Now, imagine that such a service is to be supported by a fleet of autonomous unmanned vehicles (UAV) responsible for all needed transportation tasks. We restrict the focus further to the system engineering design of such a SoS providing 
emergency ambulance service, as an application of the kind of multifaceted M\&S methodology required to effectively deal with such a complex adaptive SoS.

\subsection{Multiple Objectives}

First, consider a short list of categories of objectives relevant to the design and implementation of a new ambulance system employing unmanned autonomous vehicles (UAVs) as outlined in Table 1.

Table 1: Objectives relevant to system engineering of a UAV-based Emergency Ambulance Service.

\begin{tabular}{|c|c|c|}
\hline \# & Objectives & Models needed \\
\hline 1 & $\begin{array}{l}\text { Determine travel and payload re- } \\
\text { quirements for UAVs and per- } \\
\text { sonnel }\end{array}$ & $\begin{array}{l}\text { Kinetic models of UAVs, capacities for carrying medical } \\
\text { appliances } \\
\text { Paramedic capabilities }\end{array}$ \\
\hline 2 & $\begin{array}{l}\text { Select locations of depots and } \\
\text { deployment sites }\end{array}$ & $\begin{array}{l}\text { Real estate cost, distances involved, traffic characteriza- } \\
\text { tion }\end{array}$ \\
\hline 3 & Response policy optimization & $\begin{array}{l}\text { Centralized vs. distributed decision making of which } \\
\text { UAV to handle emergency call }\end{array}$ \\
\hline 4 & Mark & Environment: consumer tastes, competition \\
\hline 5 & Safety assurance & e plans \\
\hline 6 & $\begin{array}{l}\text { Interfacing with existing sys- } \\
\text { tems }\end{array}$ & $\begin{array}{l}\text { Coordination mechanisms, communication protocols, in- } \\
\text { teroperability }\end{array}$ \\
\hline 7 & Patient satisfaction & Waiting time, comfort, etc. \\
\hline 8 & $\begin{array}{l}\text { Determine Emergency response } \\
\text { required }\end{array}$ & $\begin{array}{l}\text { Types and frequencies of medical emergencies to be } \\
\text { treated } \\
\text { Response timelines requirements and how to meet them }\end{array}$ \\
\hline 9 & Autonomous adaptive behavior & $\begin{array}{l}\text { Ability to adapt to changing environments associated } \\
\text { with different catastrophic events }\end{array}$ \\
\hline $\mathbf{1 0}$ & $\begin{array}{l}\text { System sustainment, mainte- } \\
\text { nance and evolution }\end{array}$ & $\begin{array}{l}\text { Pricing of services, costs of equipment, investment capi- } \\
\text { tal, long term trends, unused capacity, growth potential }\end{array}$ \\
\hline
\end{tabular}

An all-inclusive model would be able to provide the basis for decision making in each of these categories. However, the impediments to constructing such a comprehensive model make it a near impossibility. Instead, we can envisage a collection of partial models, each oriented to one or more objectives (Zeigler et al. 2018a).

\subsection{Multiple Partial Models}

The following is a subset of models that were developed to address the objectives $1-3$, and $8-10$ just listed:

1. UAVMotion is a discrete event model representing the motion of the UAVs as agents in space employing only the kinetic parameters of the vehicles and the random space-time distribution of requests to get a first order prediction of the number required to meet the demand.

2. MarkovDutyCycleCTM represents the duty cycle of a typical UAV as a Markov stochastic process with a small number of states representing its location as at the depot or in the service area and able or not to provide service.

3. Multiwork represents the UAVs as individual servers in a discrete event model with a simple bidding protocol to coordinate response to incoming requests with the servers progressing through a duty cycle consistent with the Markov model. 
4. Hierarchical Composition elaborates on the Multiwork model by incorporating states of the vehicles (e.g., carrying patient) that bear upon speed of travel and available fuel. Hierarchical structure results from representation of UAV as itself a composite with components representing coordination protocols, kinetics, and fuel consumption.

5. Design for Adaptive Sustainment will be discussed in a moment.

These models were developed in the order of presentation above following the MRM construction methodology. The first model assumes vehicles are essentially point elements moving in space with abilities to respond to requests without coordination in a neighborhood. The second is a highly lumped model that represents the fleet in an ensemble sense similar to the ideal gas laws of physics. The third introduces treating vehicles as individuals requiring coordination to provide service, while the fourth elaborates on this representation to introduce more of the required constraints.

The assumptions, limitations, and contribution of each model are listing in Table 2. The developmental progression illustrates that addition of assumptions and removal of constraints does not necessarily proceed in a monotonic manner but in a manner that is guided by the incremental needs to establish bounds on predictions to come later and to develop easier structural scaffolds for later construction.

Table 2. A subset of models developed for objectives 1-3 and 8-10 of Table 1.

\begin{tabular}{|c|c|c|c|c|}
\hline Model & Assumptions & Limitations & Contribution & $\begin{array}{l}\text { Applicable } \\
\text { to } \\
\text { Objective: }\end{array}$ \\
\hline UA VMotion & $\begin{array}{l}\text { Kinetic spatial distri- } \\
\text { bution of requests, pol- } \\
\text { icy employs visibility } \\
\text { and spatial properties }\end{array}$ & $\begin{array}{l}\text { No duty cycle } \\
\text { representation } \\
\text { No startup No } \\
\text { product proper- } \\
\text { ties }\end{array}$ & $\begin{array}{l}\text { Predicts number of UAVs } \\
\text { required under fundamental } \\
\text { spatial properties }\end{array}$ & 1,3 \\
\hline $\begin{array}{l}\text { MarkovDu- } \\
\text { tyCycleCTM }\end{array}$ & $\begin{array}{l}\text { Combined stochastic } \\
\text { and deterministic rep- } \\
\text { resentation of duty cy- } \\
\text { cle }\end{array}$ & $\begin{array}{l}\text { Above limita- } \\
\text { tions + Lumps } \\
\text { UAVS into sin- } \\
\text { gle number that } \\
\text { determines ser- } \\
\text { vice rate }\end{array}$ & $\begin{array}{l}\text { Predicts numbers required } \\
\text { under simple duty cycle ap- } \\
\text { proximation }\end{array}$ & 2 \\
\hline $\begin{array}{l}\text { Multi-work- } \\
\text { flow }\end{array}$ & $\begin{array}{l}\text { UAVs individually } \\
\text { represented as servers } \\
\text { in duty cycle, UAV } \\
\text { distance to request em- } \\
\text { ployed in bidding. }\end{array}$ & $\begin{array}{l}\text { All details of } \\
\text { tasks and work } \\
\text { cycle ab- } \\
\text { stracted into } \\
\text { single service } \\
\text { time }\end{array}$ & $\begin{array}{l}\text { More refined prediction in- } \\
\text { cluding performance/cost } \\
\text { tradeoffs from Pareto fron- } \\
\text { tier }\end{array}$ & 2,3 \\
\hline $\begin{array}{l}\text { Hierarchical } \\
\text { composition }\end{array}$ & $\begin{array}{l}\text { All requirements } 1-3 \\
\text { and } 8 \text { and constraints } \\
\text { accounted for to first } \\
\text { approximation }\end{array}$ & $\begin{array}{l}\text { No spatial rep- } \\
\text { resentation, no } \\
\text { account of en- } \\
\text { ergy utilization }\end{array}$ & $\begin{array}{l}\text { Good solution approxima- } \\
\text { tion under service require- } \\
\text { ments/constraints-agrees } \\
\text { with earlier predictions }\end{array}$ & $1-3,8$ \\
\hline $\begin{array}{l}\text { Design for } \\
\text { Adaptive } \\
\text { Sustainment }\end{array}$ & $\begin{array}{l}\text { Extends Multi-work- } \\
\text { flow model with eco- } \\
\text { nomic UAV "earn their } \\
\text { keep" mechanism and } \\
\text { modification of fleet } \\
\text { size }\end{array}$ & $\begin{array}{l}\text { Same as } \\
\text { UAVMotion } \\
\text { plus simplifica- } \\
\text { tion of eco- } \\
\text { nomics and } \\
\text { fleet size modi- } \\
\text { fication }\end{array}$ & $\begin{array}{l}\text { Can predict dynamics of } \\
\text { "carrying capacity" includ- } \\
\text { ing fleet size variation in re- } \\
\text { sponse to varying demand } \\
\text { environment }\end{array}$ & 9,10 \\
\hline
\end{tabular}




\begin{tabular}{|c|c|c|c|c|}
\hline $\begin{array}{l}\text { Design for } \\
\text { Adaptive Sus- } \\
\text { tainment } \\
\text { Lumped } \\
\text { Model }\end{array}$ & $\begin{array}{l}\text { Uniformity and Ran- } \\
\text { dom phase assump- } \\
\text { tions enable simplifica- } \\
\text { tion. }\end{array}$ & $\begin{array}{l}\text { DEVS Markov } \\
\text { Lumped Model } \\
\text { not for detailed } \\
\text { simulation }\end{array}$ & $\begin{array}{l}\text { Can predict "carrying ca- } \\
\text { pacity" including fleet size } \\
\text { equilibrium in fixed de- } \\
\text { mand environment }\end{array}$ & 10 \\
\hline
\end{tabular}

\section{UAV DESIGN FOR ADAPTIVE SUSTAINMENT}

The fifth model directly relates to modeling of complex adaptive SoS for system engineering design. Such a design might search for architectures in a trade-off space involving size and cost. Here, for example, half the number of UAVs at, say, half the cost, might be enough to ensure a response time that is only $10 \%$ higher than nominally specified. However, rather than the systems engineer having to determine the fleet size prior to fielding, s/he might design upper/lower brackets within which to constrain an adaptive plan. This might be similar to the way in which the number of Uber drivers in a town adjusts to its passenger demand. Such "design for adaptive sustainment" objectives call for inclusion of models of the environment in which adaptation is occurring as well as of the mechanism mediating the process. A wide variety of such representations is available at different levels of abstraction and computational complexity with typical parallels drawn to biologically inspired learning and evolutionary processes (Vasbinder and Gao 2018; Sutton and Barto 1998). One possibility that seems especially apt here (and is rarely considered) rests on the analogy to the carrying capacity of an ecosystem for a member species. Here, a species dynamically adjusts to a population size in which it is in equilibrium with the resources necessary to sustain it (Arrow 1995). Analogously to build in such self-adjustment into a fleet of UAVs requires an economic mechanism in which UAVs must "earn their keep" and means for infusion/withdrawal of UAVs to/from the operating fleet. Such adaptive models can be tested in simulation and fielded with little change in code using model continuity methods (Zeigler and Sarjoughian 2017).

\subsection{Parameters That Control Fleet Size Behavior}

Before proceeding we list parameters and associated information that will be discussed subsequently. The reader may come back to this table for explanations when needed.

Table 3: Parameters and Associated Information.

\begin{tabular}{|l|l|l|l|}
\hline Parameter & Definition & Meaning & Assumptions \\
\hline $\begin{array}{l}\text { Avg. Inter-Request } \\
\text { Time }\end{array}$ & Inverse of Request Rate & $\begin{array}{l}\text { Requests are } \\
\text { generated in by a } \\
\text { Poisson process }\end{array}$ & $\begin{array}{l}\text { Assumed to change in } \\
\text { piecewise constant manner } \\
\text { over time }\end{array}$ \\
\hline Avg. Service Time & $\begin{array}{l}\text { Average time to fulfill a } \\
\text { service request }\end{array}$ & $\begin{array}{l}\text { Assumed to remain } \\
\text { constant }\end{array}$ \\
\hline Consumption Rate & $\begin{array}{l}\text { The rate at which savings } \\
\text { are consumed }\end{array}$ & $\begin{array}{l}\text { Consumption } \\
\text { interacts with } \\
\text { service as } \\
\text { elaborated in text }\end{array}$ & $\begin{array}{l}\text { Assumed to remain } \\
\text { constant }\end{array}$ \\
\hline Max. Savings & $\begin{array}{l}\text { Value of savings at which } \\
\text { replication occurs }\end{array}$ & $\begin{array}{l}\text { The higher this } \\
\text { threshold, the } \\
\text { lower the }\end{array}$ & $\begin{array}{l}\text { Assumed to remain } \\
\text { constant }\end{array}$ \\
\hline
\end{tabular}


Zeigler and Kim

\begin{tabular}{|c|c|c|c|}
\hline & & $\begin{array}{l}\text { frequency of } \\
\text { replication }\end{array}$ & \\
\hline Min. Savings & $\begin{array}{l}\text { Value of savings at which } \\
\text { removal from fleet occurs }\end{array}$ & $\begin{array}{l}\text { Negative value } \\
\text { allows some "in } \\
\text { the red" savings } \\
\text { to prevent rapid } \\
\text { decrease in fleet } \\
\text { size }\end{array}$ & Assumed to remain at 0 \\
\hline $\begin{array}{l}\text { Number of } \\
\text { replicates }\end{array}$ & $\begin{array}{l}\text { The number of new } \\
\text { UAVs added to the fleet } \\
\text { when replication occurs }\end{array}$ & $\begin{array}{l}\text { The higher this } \\
\text { number, the faster } \\
\text { the fleet growth }\end{array}$ & $\begin{array}{l}\text { Assumed to remain } \\
\text { constant }\end{array}$ \\
\hline Pay & $\begin{array}{l}\text { The amount paid for } \\
\text { service after completion }\end{array}$ & $\begin{array}{l}\text { For basic survival, } \\
\text { the pay must } \\
\text { cover the } \\
\text { consumption of } \\
\text { savings until the } \\
\text { next service } \\
\text { completion. }\end{array}$ & $\begin{array}{l}\text { Assumed to remain } \\
\text { constant }\end{array}$ \\
\hline Request Rate & $\begin{array}{l}\text { Rate of arrival of requests } \\
\text { for service } \\
\text { (instantaneous) }\end{array}$ & $\begin{array}{l}\text { Represents time } \\
\text { varying demand }\end{array}$ & \\
\hline Service Rate & $\begin{array}{l}\text { Inverse of Avg. Service } \\
\text { Time }\end{array}$ & $\begin{array}{l}\text { The service time } \\
\text { is sampled from } \\
\text { an exponential } \\
\text { distribution with } \\
\text { the given service } \\
\text { rate. }\end{array}$ & \\
\hline
\end{tabular}

\subsection{Design for Adaptive Sustainment Base Model}

The Design for Adaptive Sustainment model extends multi-workflow model with economic UAV "earn their keep" mechanism and modification of fleet size. UAVs that are idle bid for the opportunity to fulfill a request. The bid winner services the request over a time drawn from a probability distribution. In a rich demand environment, modeled by a high rate of request arrivals, a UAV is able to accumulate enough savings so that it can "replicate" i.e., cause one or more UAVs to be added to the fleet. If the environment declines (demand for service decreases), a UAV whose savings vanish "dies" (is removed from the fleet). Designs for this "hire/fire" adaptive mechanism can be tested by simulation. Lumped model simplification can be created to enable combined simulation-based prediction and analytical reasoning of the dynamics of adapting to changes in demand and bracketing of the equilibrium (carrying capacity) fleet size. The base model is a simulation model constructed in MS4 Me (ms4systems.com) that derives from the multi-workflow model by simplifying the duty cycle while adding in the economic survival. In this model, UAVs are individually represented as servers where all details of tasks and duty cycle abstracted into a single service time. UAVs bid for incoming requests; however rather than UAV distance to request factored in, the bidding is based on fastest response (which is a coordination policy that is easy to implement in the discrete event context. In contrast to the source multi-workflow model, fleet size is not independently set as a parameter but arises from the dynamics of the model per se. Therefore questions arise as to what are the 
performance metrics and how can they be influenced by parameters. After gaining some understanding of the model behavior we return to these questions later.

\subsection{Markov Lumped Model: Necessary Condition for UAV Survival}

We start with a lumped model of the base model just introduced. Figure 1 illustrates a DEVS Markov Model of an individual UAV agent's behavior as a lumped model derived from the combined workflow and survival perspective. In addition to its control states (Waiting, Working, and Dead), the model keeps track of the Savings i.e., income minus consumption, at any time. While in the Waiting state, the model incurs a decrement in Savings, computed as the waiting time multiplied by the consumption rate. The model can remain in Waiting for, at most, its LifeTime computed as the current Savings divided by the consumption rate. Consumption represents the cost of operation and maintenance including energy consumed. Income occurs only at the end of service of a request (arrival of which is an external event). Upon termination of service, the agent's savings are 1) decreased by the incurred consumption (i.e., service duration multiplied by the consumption rate) and 2) increased by the payment received for the service. Inspecting the figure, we see that starting from an initial Savings equal to the payment, the LifeTime must exceed the service time plus the waiting time for the agent to survive. When the request rate is much higher than the service rate, the waiting time is (near) zero and we find that the payment must exceed the service duration multiplied by the consumption rate. This is a necessary condition for survival. It is not sufficient, since the waiting time can increase as the request rate decreases. This happens in a competitive environment as the UAV fleet expands and individual UAVs must wait for their bid to be successful to get the go ahead to perform the current requested service.

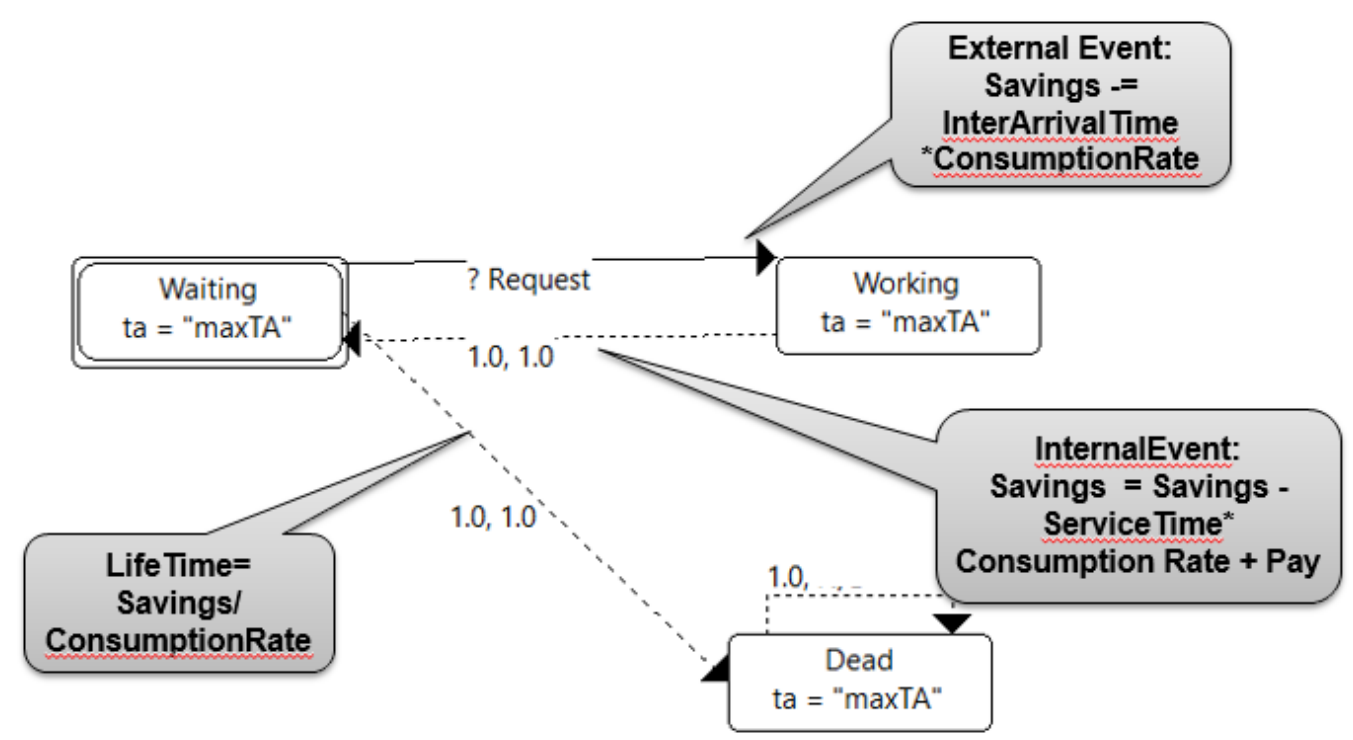

Figure 1:DEVS Markov Model of UAV. Legend: ? external event,

--- line: internal event with labelled probability and mean time.

\subsection{Adaptation of Fleet Size to Increased Request Rate}

To account for adaptive response of the fleet, we must expand the individual model of Figure 1 to represent the fleet size in an aggregated manner. To do this, we add a statements to the tag block for the internal transition from Working to Waiting that test if the Max. Savings is exceeded and if so increments the fleet size and increases the Avg. Inter-Request Time accordingly (see (Zeigler and Sarjoughian 2017) for an exposition of the tag block in the MS4 Me implementation of DEVS). This is a crucial point: in the bidding process, each idle server has the same winning probability so that the effective average time to a next request 
for any UAV is inversely related to the fleet size (see (Zeigler et al. 2018a) for a discussion of validity of this aggregation). Since the LifeTime is the sum of inter-request and service times, the effect of reducing inter-request time becomes significant only when the inter-request time becomes of the same magnitude as the service time. This explains the behavior in Figure 2 which illustrates the response of the UAV fleet to an increase in request rate. The trajectory of the UAV fleet size goes through an initial fast growth phase, then enters a slow growth phase, and equilibrates in a steady state which is the carrying capacity.

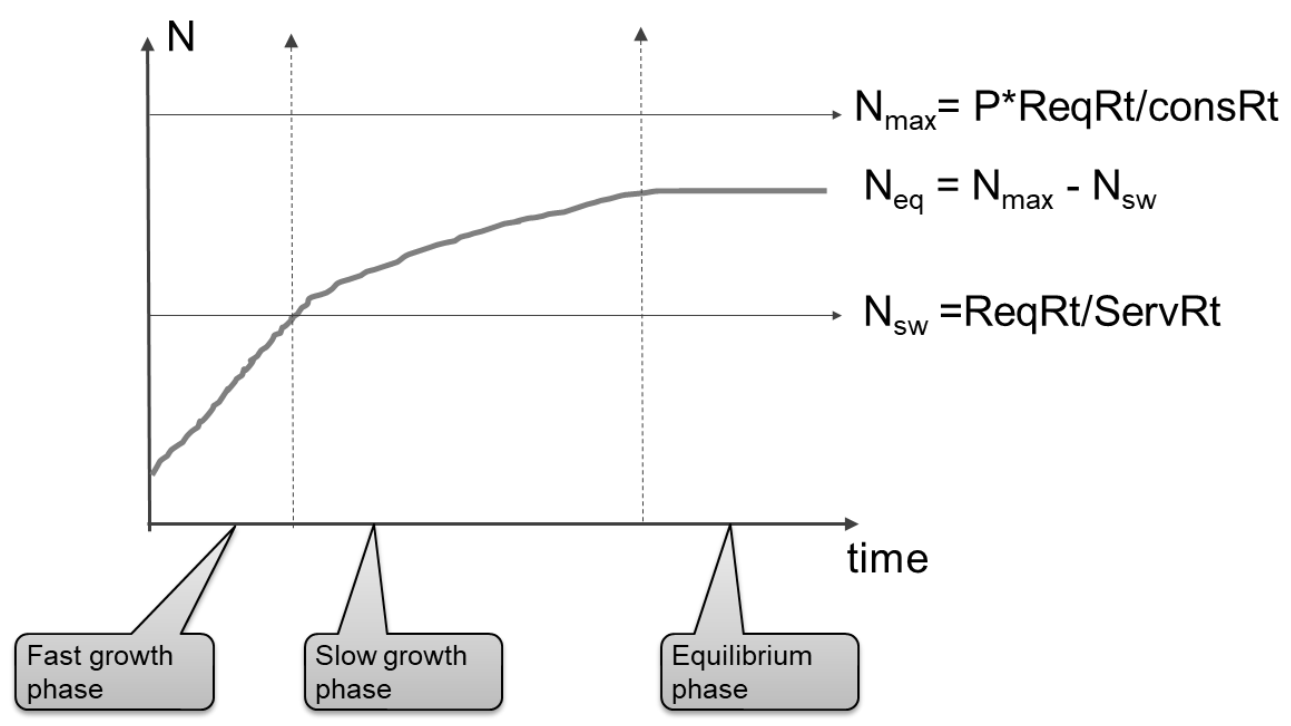

Figure 2: Adaptation to Higher Request Rate. Plot of Fleet size N against time, $\mathrm{P}=$ Payment amount per service, consRt $=$ consumption rate, $\mathrm{ReqRt}=$ request rate, ServRt $=$ service rate. See text for discussion of $\mathrm{N}_{\mathrm{Max}}, \mathrm{N}_{\mathrm{SW}}$, and $\mathrm{N}_{\mathrm{eq}}$.

The fast growth occurs during the initial period when the average effective inter-request time is small compared to the average service time. The slow growth phase starts when the effective interrequest time becomes equal to the average service time. At this point, the fleet size equals the request rate divided by the service rate, shown as the switching size, $\mathrm{N}_{\mathrm{Sw}}$ in Figure 2. The trajectory can continue to ascend toward $\mathrm{N}_{\mathrm{Max}}$ which is the maximum size that is consistent with each UAV earning the minimum payment required for survival (recall Sec. 3.3). The levels $\left[\mathrm{N}_{\mathrm{Sw}}, \mathrm{N}_{\mathrm{Max}}\right]$ bracket the equilibrium level $\mathrm{N}_{\text {eq. }}$. Equilibrium, where the fleet size remains constant, is characterized by the invariance of Savings over time (if Savings increased then eventually size would increase; similarly, Savings can't continue to decrease). From the model logic this implies that service time plus inter-request time equals Pay/consumption rate. Since inter-request time is inversely related to the fleet size, some manipulation gives us the expression for $\mathrm{N}_{\text {eq }}$ shown in Figure 2. Further, we can easily derive a simple relationship for the conditions under which the equilibrium settles at the switching level - we find that Pay=2 consRt/ServRt just in case $\mathrm{N}_{\text {eq }}=$ $\mathrm{N}_{\mathrm{SW}}$ in which case we also have $\mathrm{N}_{\mathrm{eq}}=\mathrm{N}_{\mathrm{Max}}$. This relationship provides an easy setting for payment level that can be used for simulation-based testing of the lumped model and base models consistency.

\subsection{Adaptation of Fleet Size to Decrease in Request Rate}

Figure 3 illustrates the response of the UAV fleet to a decrease in service request rate. The trajectory of the UAV fleet size drops from the carrying capacity at the original request rate to the lower carrying capacity 
at the lower request rate. We reason that, with only the request rate changing, the fleet size can only go lower because equilibrium depends explicitly on request rate. Although shown as smoothly converging to equilibrium, the trajectories shown can actually display oscillations in approaching the carrying capacity, as discussed next.

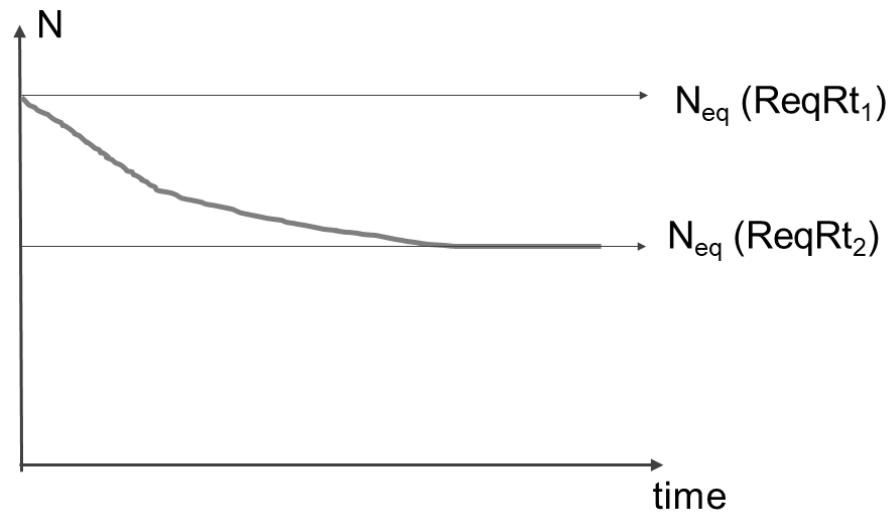

Figure 3: Adaptation to Lower Request Rate Plot of Fleet size N against time, dependence of carrying capacity $\mathrm{N}_{\mathrm{eq}}$ on request rate $\left(\mathrm{ReqRt}_{2}<\mathrm{ReqR}_{1}\right)$.

The plots in Figures 2 and 3 were derived from analysis of the lumped model introduced in Section 3 . The relationships derived provide a basis for simulation of both the lumped and base models. Simulation experiments confirmed the basic relationships. One such result of a lumped model simulation run appears in Figure 4. It shows fluctuations of fleet size (red) around the predicted equilibrium (green) for particular settings of the parameters. Figure 5 shows a base model simulation run in which the fleet size adapts to a fall in demand and recovers as the demand subsequently rises to its original level.

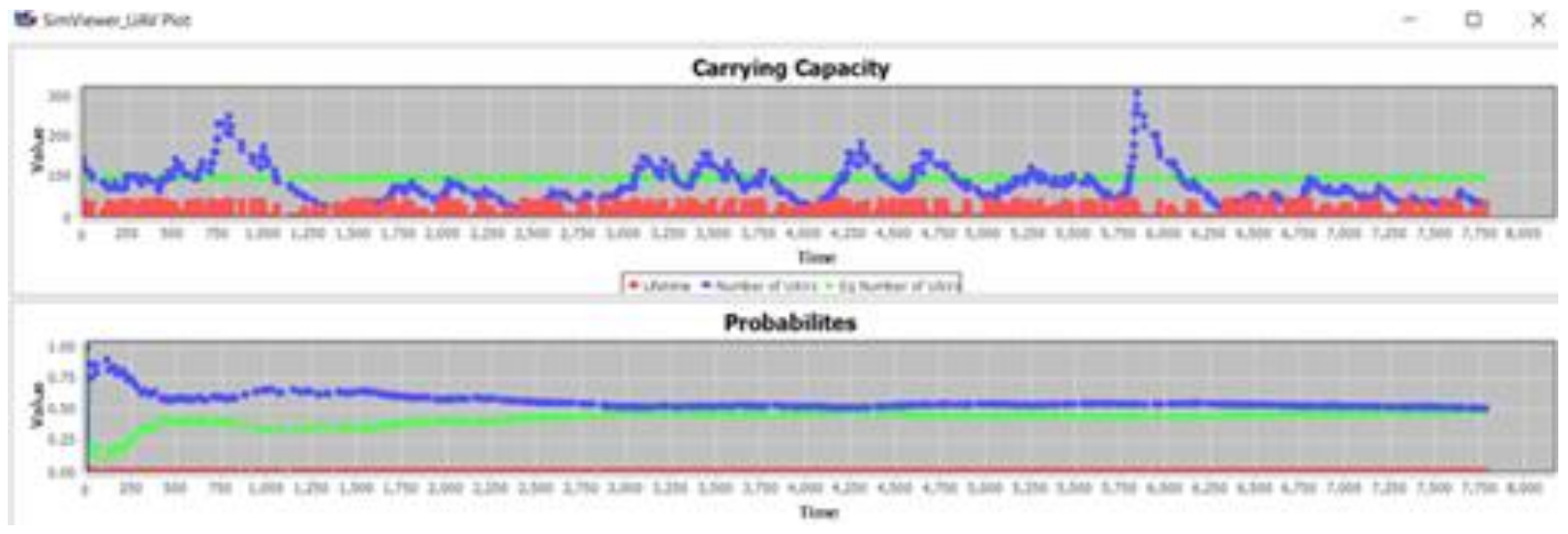

Figure 4: Lumped model example: Upper plot of Fleet size (blue) as it fluctuates around equilibrium level (green); lower plot showing convergence of probabilities of states Waiting and Working to equal values. 


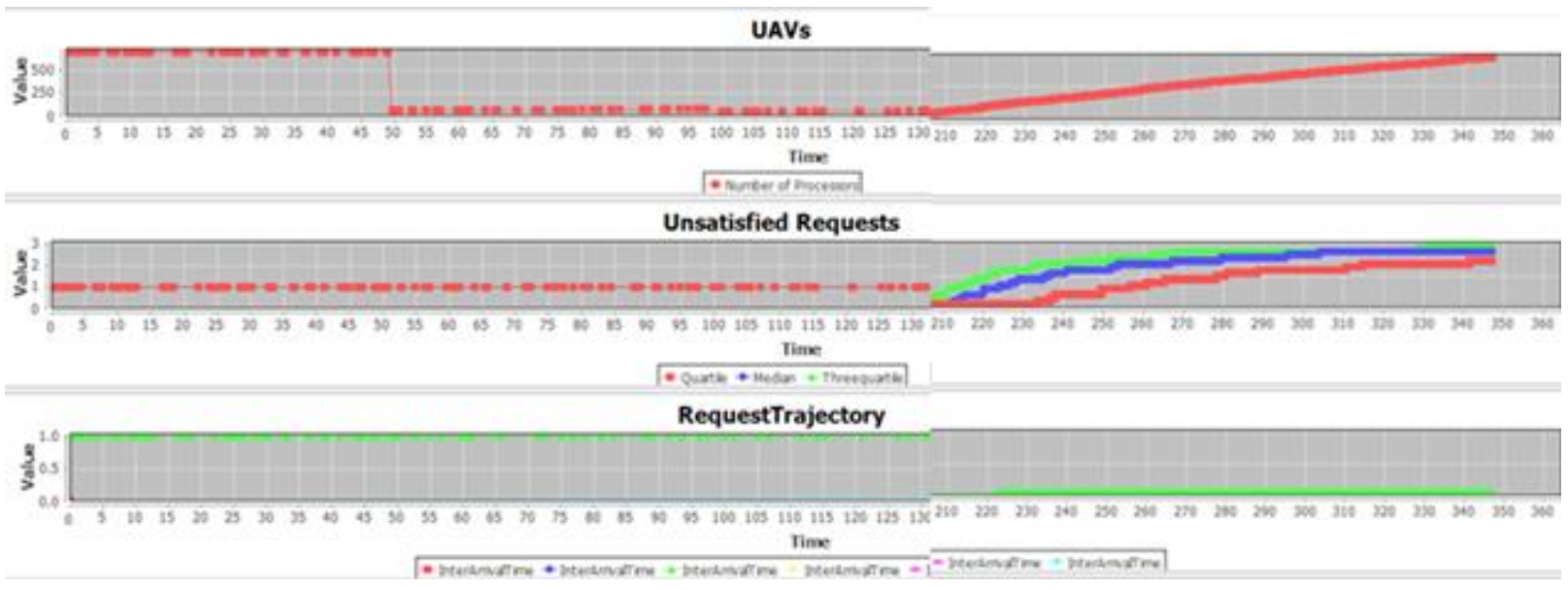

Figure 5: Base Model Example: Upper plot of Fleet size (UAVs) as it starts at high level and drops to low level then rises back to high level as the average inter-request time falls to $10 \%$ of its original value. The unsatisfied requests increase with this increased demand until the fleet size recovers its original size.

\section{AUTOMATED SEARCH THROUGH ARCHITECTURAL ALTERNATIVES}

The Automated Scenario Construction (ASC) architecture envisions a collaboration between human and AI agents while offering a generic workflow for SoS model development (Zeigler et al. 2018b). The human modeler develops the System Entity Structure (SES) (Zeigler and Sarjoughian 2017) and the DEVS model base to span the configuration space that encompasses the model family of interest. The AI agent, under control of the user, analyses the results and generates new prunings to find models that satisfy the desired experimental frames. The modeler develops valid simplification morphisms for the DEVS base and lumped models and decides when and how to iterate between the levels of resolution in order to accelerate the overall process. Here, any equivalence between base and lumped models allows the latter model to stand in for the former for the objectives.

Consideration of design for adaptive sustainment objectives begins with requirements to achieve desired performance levels for service. In the emergency ambulance context every request must be satisfied and moreover there is a time frame within which the service must be completed. Moreover, the adaptive aspect adds consideration of characteristics of adaptive response. For example, the response to changes in the demand environment must satisfy requirements of speed and accuracy. Simulation of the DEVS base model is required to get reliable results in search for values of the parameters in Table 1 that produce desired values of metrics that implement these requirements. The ASC technology supports setting up the configuration space for the adjustable parameters and searching through it for regions of interest.

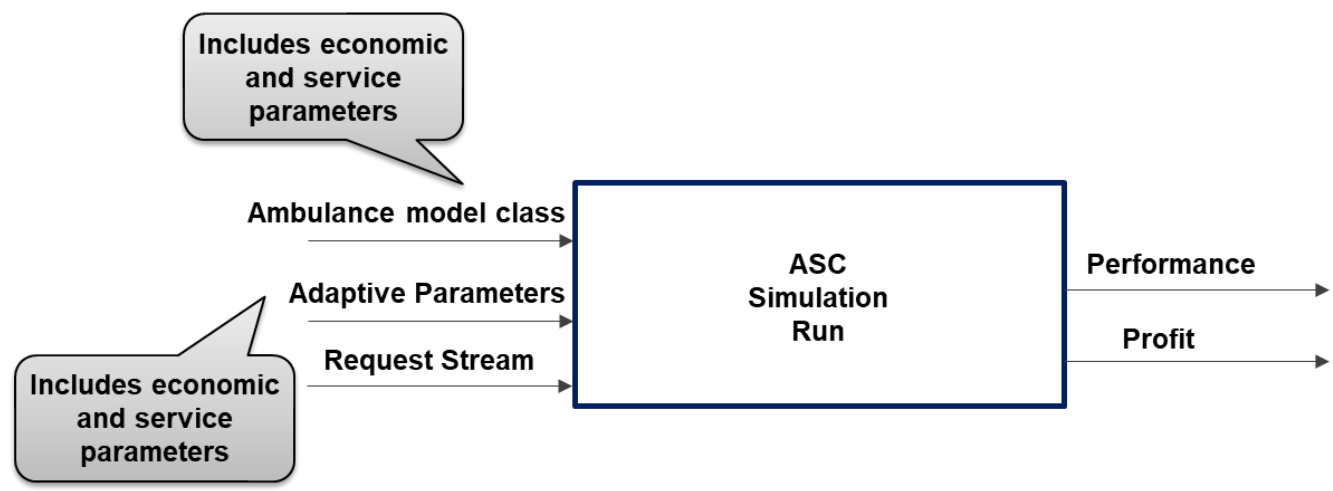

Figure 6: Automated Scenario Construction technology for evaluation of UAV system proposals. 
The configuration space takes on greater complexity when architectural constraints are included in the problem. Figure 6 considers a design space formulated by proposals offered by various companies to field the UAV fleet. Each proposal offers a fleet consisting of its own ambulance model class with associated economics, viz.: Pay (charge to customer for service) and Consumption Rate (operation and associated costs) as well as service capabilities (Avg. Service Time). Of course, all proposals are subject to the same demand environments (Request Rate) both static and dynamic. With demand environment specified and economic and service parameters constrained by each proposal, the remaining adaptive mechanism parameters (Max. Savings, Min. Savings, Number of replicates) are to be freely selected. Thus, the search space is spanned by proposed architectures with each simulation run producing a pair: Service Performance and Profit. Here service performance is measured by the percentage of requests that were satisfied within the specified time frame. Profit is measured by the sum of all Savings in the UAVs of the fleet at the end of a run. The final results can be presented in a scatter plot in which alternatives are represented by their pairs (performance, profit). These points are bounded by the Pareto frontier that identifies the best performer at each profit level. The ASC employs a strategy for managing the simulation budget for such multicandidate stochastic searches that is similar to that of Choi, Kang, and Kim (2019).

\section{CONCLUSIONS AND FURTHER RESEARCH}

Modeling and simulation are activities undertaken to support system engineering decision making — the ability to assess the effects of constructions and interventions before they are actually carried out and to pre-select promising ones, in view of the driving objectives. These objectives in turn serve to orient modeling efforts. With the advent of Unmanned Autonomous Vehicles (UAV), new kinds of systems of systems (SoS) that provide specific services may be on the horizon. We recognize that beyond basic technology requirements, such UAV-based service systems may be subject to a multiplicity of system engineering objectives. An all-inclusive model would be able to provide the basis for decision making in each of such categories as payload requirements, on-board-energy constraints, locations of depots/launch sites, and so on. However, the cognitive and computational impediments to constructing such a comprehensive model make it a near impossibility. Instead, Multiresolution modeling helps us to construct a collection of partial models, each oriented to one or more objectives. Here we discussed a Modeling and Simulation methodology that is based on Discrete Event System Specification (DEVS) and System Entity Structure (SES) and Automated Scenario Construction technology. We illustrated the approach by focusing on Design for Adaptive Sustainment with UAVs in a fleet possessing economic "earn your keep" mechanisms and modification of fleet size. Full scale architecture search and simulation is needed to predict dynamics of "carrying capacity" including fleet size variation in response to varying demand environments. However, insight into the effects of parameter values, and reasoned guidance for architecture search is fostered through construction of simplified DEVS Markov lumped models (supported by MS4 $\mathrm{Me}$, a reason for their use). As implemented in the MS4 Me integrated development environment, this approach provides a practical approach to multifaceted system design of UAV-based service systems. While the MRM methodology illustrated here was phrased in terms of DEVS/SES, the methodology might well be supported in other M\&S frameworks, a potential direction for future research. A family of models developed to address the multiple objectives needed must be decided according to standards, decisions, and trade-offs, involved in the MRM process. Questions raised by reviewers include "Who/What decides model set partitioning?", "How much performance is sacrificed in such selections?", and "Can these decisions be automatically analyzed?" These questions concern simulation model engineering and can be the basis for fruitful future research.

\section{REFERENCES}

Arrow, K. 1995. Economic Growth, Carrying Capacity, and the Environment Science.. Ecol. aEcon., 15, 91-95, doi:10.1126/science.268.5210.52 
Choi S.H, B. G. Kang, and T. G.Kim, 2019. A Heuristic Procedure for Selecting the Best Feasible Design in the Presence of Stochastic Constraints, IEEE TRANS. SYS., MAN, AND CYBER:SYSTEMS (https://www.mdpi.com/2079-8954/6/4/40/htm)

Dahmann, J. 2018. Systems Engineering Guide., MITRE Publication, McLean VA, . https://www.mitre.org/publications/systems-engineering-guide/about-the-seg (accessed November 11, 2018).

Davis, P.K. and J.H. Bigelow. 2007. Experiments in Multi Resolution Modeling (MRM). Technical Report, Rand: Santa Monica, CA, USA, 1998. https://www.rand.org/content/dam/rand/pubs/monograph_reports/2007/MR1004.pdf (accessed on November 11, 2018).

NPS Faculty. 2017. Aggregated Combat Models, Available online: http://faculty.nps.edu/awashburn/Washburnpu/aggregated.pdf (accessed on 3 April 2017).

Sutton, R.S. and A.G. Barto. 1998. Reinforcement Learning: An Introduction, Bradford Book, MIT Press: Cambridge, MA, USA

Vasbinder, J.W. and H. Gao. 2018. Selected Papers Of John H. Holland: A Pioneer In Complexity Science, World Scientific Press: Singapore.

Zeigler, B.P. and H. Sarjoughian. 2017. Guide to Modeling and Simulation of System of Systems, Springer: New York, NY, USA.

Zeigler, B.P., A. Muzy, A. and E. Kofman. 2018a. Theory of Modeling and Simulation, 3rd Edition; Academic Press: New York, NY, USA.

Zeigler, B.P., S. Mittal, and M.K. Traore. 2018b. MBSE with/out Simulation: State of the Art and Way Forward, Systems 2018, 6(4), 40; https://doi.org/10.3390/systems6040040

\section{AUTHOR BIOGRAPHIES}

BERNARD ZEIGLER Bernard P. Zeigler is Professor Emeritus of Electrical and Computer Engineering at the University of Arizona, Tucson, AZ, USA and Chief Scientist of RTSync Corp., Phoenix, AZ, USA. $\mathrm{He}$ is internationally renowned for his seminal contributions in modeling and simulation theory. He is well known for the Discrete Event System Specification (DEVS) formalism that he invented in 1976 and which is now being used world-wide in advanced information systems. Dr. Zeigler is a Fellow of the SCS and received the INFORMS Lifetime Achievement Award. In 1995, he became Fellow of the IEEE in recognition of his theory of discrete event simulation. He is an Emeritus Professor with the Arizona Center of Integrative Modeling and Simulation, Tempe, AZ, USA, and a Chief Scientist with RTSync Corp, Chandler, AZ, USA, and MD, USA. His e-mail address is zeigler@rtsync.com.

DOOHWAN KIM Dr. Doohwan Kim is the founder and CEO of RTSync corporation, a company which specializes in testing and evaluation, predictive analytics, and risk assessment tools and services based on advanced modeling and simulation technologies. He has been involved in the design, development and delivery of the advanced $M \& S$ solutions for highly complex real world information science and engineering problems for US Dept of Defense, Homeland Securities, NASA, and NSF. He received his Ph.D. from the Department of Electrical and Computer Engineering of the University of Arizona. Dr. Kim can be reached atdhkim@rtsync.com. 